\title{
Contextualizando a invasão à Baia dos Porcos
}

\author{
Contextualizing the invasion of the Bay of Pigs
}

DÉBORAH BARROS LEAL FARIAS*

Rev. Bras. Polít. Int. 51 (1): 105-122 [2008]

\section{Introdução}

Em 17 de abril de 1961, entre 1.500 e 1.800 exilados cubanos contrários ao governo do presidente de seu país, Fidel Castro, e treinados pela Agência Central de Inteligência norte-americana (CIA), aportaram na Baía dos Porcos, localizada ao sul de Cuba. A ação, que acabou dois dias depois, na tarde do dia 19 do mesmo mês, fracassou completamente, com 114 mortos e quase 1.200 invasores capturados.

O objetivo imediato da investida era ter o controle do sul do território cubano nas mãos daqueles contrários ao governo de Fidel Castro (no poder desde o início de 1959), e em seguida avançar pelo país colhendo apoio da população para derrubar o regime vigente. No entanto, a operação foi mal-preparada, não houve apoio militar explícito dos EUA, e a população local mostrou-se defensora do governo revolucionário. $\mathrm{O}$ resultado foi um grande constrangimento para a administração de John F. Kennedy, presidente dos EUA, que foi forçada a admitir ter organizado a operação.

Um olhar mais atento revela uma significativa complexidade histórica por trás dos fatos. Com tal objetivo em mente, o presente trabalho pretende demonstrar as principais circunstâncias que levaram os Estados Unidos a promoverem a invasão à Baía dos Porcos. Assim, buscar-se-á demonstrar que vários foram os elementos importantes que influenciaram nesta decisão, entre os quais se listam a tradição de política externa norte-americana de interferir na região centro-americana e caribenha; o recente sucesso obtido na derrubada do presidente guatemalteco; e questóes de política externa e interna norte-americana frente à Guerra Fria.

Para isso, será inicialmente realizado um breve estudo histórico sobre Cuba e a mudança política ocorrida com a ascensão de Fidel Castro, em 1959. Em seguida, serão avaliados os fatores considerados como principais para a decisão

\footnotetext{
* Doutoranda em Ciência Política pela University of British Columbia (Estados Unidos), mestre em Relações Internacionais pela Universidade de Brasília - UnB e professora da Universidade de Fortaleza - Unifor (deborahbarrosleal@gmail.com).
} 
norte-americana de intervir no território cubano. O primeiro desses fatores será a presença (histórica) militar e/ou intervencionista norte-americana, desde o final do século XIX, nos países banhados pelo Mar do Caribe até a administração de Dwight Eisenhower (1953-1961). O segundo elemento avaliado, será a (bem sucedida) experiência da participação da CIA na derrubada do presidente guatemalteco Jacobo Arbenz, em 1954. Por fim, far-se-á uma análise do impacto da Guerra Fria na política externa e doméstica dos EUA, o contexto político e fatores imediatos que levaram o presidente John F. Kennedy a decidir autorizar a invasão.

\section{Sobre Cuba e sua revolução}

Com uma área de 110 mil km², e uma população 11,4 milhões (est. $\left.2007^{1}\right)$ composta por mulatos, brancos, negros e descendentes de chineses, Cuba encontra-se entre o Mar do Caribe, o Golfo do México e o Oceano Atlântico, a apenas a $150 \mathrm{~km}$ do sul das ilhas de Key West (Florida), Estados Unidos.

Colonizada por espanhóis, Cuba foi "descoberta” por Cristóvão Colombo em 1492. Em meados do século XIX passam a crescer os movimentos internos pela independência da ilha do controle ibérico, inclusive contando com a declaração de independência (não reconhecida) proferida por Carlos Manuel de Céspedes (1868), que deu início a uma guerra civil com os espanhóis e que terminaria com a vitória desses, em 1878 . Uma outra grande referência na luta pela libertação cubana foi o herói nacional José Martí, assassinado em 1895.

No entanto, a ruptura de Cuba com a Espanha não foi obtida por iniciativa própria. Teve como marco a guerra travada entre os Estados Unidos e a Espanha pelo controle da ilha, que durou pouco mais de dez semanas, e da qual os EUA saíram vitoriosos. A questão da independência cubana frente a esse resultado ficou marcada por dois documentos jurídicos norte-americanos.

O primeiro, de autoria do (anti-imperialista) Senador Henry Teller, conhecido como Emenda Teller (1898), serviu para garantir à opinião pública norte-americana que o país não tinha intenção de anexar $\mathrm{Cuba}^{2}$, e afirmava:

That the people of the Island of Cuba are, of right ought to be, free and independent.

(...)

[the United States] hereby disclaims any disposition of intention to exercise sovereignty, jurisdiction, or control over said island except for pacification thereof, and asserts its determination, when that is accomplished, to leave the government and control of the island to its people." (grifo nosso)

1 Fonte: CIA World Factbook 2007.

2 Apesar de Cuba não ter sido anexada aos EUA, Guam, Porto Rico e as Filipinas passaram a ser efetivamente controlados pelos EUA, de forma não menos imperialista do que fariam países europeus. 
No entanto, a independência real da ilha não ocorreu conforme planejado. Ao exercerem pelo voto o direito de eleger seus representantes, ao invés de escolherem candidatos apoiados pelos norte-americanos os cubanos penderam para candidatos mais "radicais". Essa, entre outras circunstâncias, motivou políticos nos EUA a re-interpretarem, em 1901, seu papel em Cuba, o que levou à aprovação da Emenda Platt.

Elaborada pelo Senador Orvile Platt, a Emenda foi aprovada pela Convenção Constitucional Cubana (após seis rejeições), e tornou Cuba, na prática, um protetorado dos EUA. O texto permitia a esse país controlar assuntos internos cubanos, como a política externa e obtenção de empréstimos externos, além de afirmar que os governo cubano consentia que os EUA pudessem "exercer o direito de intervir pela preservação da independência de Cuba, pela manutenção de um governo adequado para a proteção da vida, propriedade e liberdade individual". ${ }^{3}$ A retirada formal dos EUA da ilha se deu em 1902. Porém, a intervenção baseada na Emenda Platt só terminaria mais de três décadas depois, em 1934.

Com o passar do tempo, os investimentos norte-americanos em Cuba, notadamente na indústria açucareira, foram aumentando progressivamente, a ponto de, já em 1923, 3/4 da propriedade voltada para esse setor pertencer a investidores estadunidenses. ${ }^{4}$

As três primeiras décadas de Cuba como país independente foram marcadas, segundo material do Centro de Información para la Prensa [Cubana] (entidade estatal), da seguinte forma:

La corrupción en su máxima expresión, se estableció como práctica en la administración pública. Los fondos que se debían invertir para obras públicas, educación y salud, eran malversados por el aparato administrativo, el Parlamento y el Poder Judicial, estos existían únicamente, para servir los intereses de los monopolistas yanquis y burgueses. La discriminación racial, la prostitución y el juego, florecieron en esa etapa. ${ }^{5}$

Em 1933, a chamada "Revolta dos Sargentos", liderada por Fulgêncio Batista, pôs por terra o governo vigente. Direta ou indiretamente, Batista governaria a ilha até sua derrubada por Fidel Castro, no último dia de 1958.

Durante "seus governos", Batista findou por trair por completo o movimento revolucionário que o havia levado ao poder, exerceu seu poder de forma ditatorial, e agravou todos os problemas relativos à má administração pública e corrupção.

Em 1952 Batista promoveu um golpe militar e passou a governar de forma ditatorial e (ainda mais) corrupta, resultado de manobras de grupos reacionários

3 Artigo $3^{\circ}$ da Emenda Platt. Além disso, ainda criou a condição para que os EUA instalassem a Base militar de Guantánamo.

4 Dado do Centro de Información para la Prensa Cubano (www.cip.cu), acesso 30.06.2007.

5 Disponível em http://www.cip.cu/webcip/libros/rev_cubana/historia/sint-historica/rev-002.html; acesso em 30.06.2007. 
cubanos e norte-americanos. Para a maior parte da população cubana, ele representava a personificação de dois males: a tirania e a exploração pelos EUA.

Fidel Castro, aos 26 anos, estava perto de ser eleito para o Congresso cubano quando ocorreu o golpe de Batista. No ano seguinte, em julho de 1953, organizou uma frustrada tentativa de derrubada do governo golpista, sendo preso e condenado a 15 anos de prisão. Foi entretanto beneficiado por uma anistia geral concedida em 1955.

\section{A Revolução Cubana}

Após sua libertação, Fidel Castro resolveu exilar-se no México, de onde planejou um novo ataque para derrubar o governo de Fulgêncio Batista. Em dezembro de 1956, Castro e outros 82 homens desembarcam do navio Granma em território cubano, e foram surpreendidos por uma emboscada, da qual a maior parte não conseguiu escapar, sendo mortos ou presos.

Entre os que conseguiram fugir estavam Fidel Castro, seu irmão, Raúl Castro, e o grande aliado Che Guevara. Os sobreviventes foram buscar refúgio na Sierra Maestra, e passaram a agir através de um movimento de guerrilha, chamado M-26-76 , que passou a ganhar cada vez mais fôlego no decorrer de 1957 e 1958. Um artigo do jornal The New York Times, de 2 de novembro de 1958, dizia:

There is not doubt that Castro's forces are better versed in guerrilla warfare than the Government troops. Batista has incorporated into his armed forces of some 40,000 men, 10,000 new recruits who are given a couple of months training but are no match for Castro's veteran guerrillas. ${ }^{7}$

No início de dezembro de 1958, as forças contrárias a Batista já controlavam um terço da ilha, mesmo contando com menos armas e recursos materiais. No decorrer do último dia de 1958 a resistência do governo findava, e a capital, Havana, passava a ser controlada pelos revolucionários. É o momento em que Fulgêncio Batista e outras altas autoridades fogem do país, marcando o primeiro dia de 1959 como a data "oficial" da Revolução Cubana.

Apesar de todo a ligação "especial" entre Cuba e URSS dos anos 60 até o fim da Guerra Fria, os vínculos imediatos da Revolução com o comunismo ou com a União Soviética eram, no mínimo, bastante frágeis. O Partido Socialista Popular (PSP), por exemplo, que se dizia o único partido da classe trabalhadora cubana, chegou a opor-se e até mesmo sabotar as ações do movimento revolucionário. E até meados de 1958, os comunistas cubanos continuaram a insistir que Batista só poderia ser derrubado por um levante popular por eles liderado (Andrew \&

6 Movimento 26 de Julho, em homenagem à data de 1953 em que Fidel Castro e seus aliados tentaram derrubar o governo de Batista.

7 “Castro's Power At Peak On Eve of Cuban Vote”. The New York Times, 02/11/1958, página 4E 
Gordiewsky, in: BANDEIRA, 1998:171). Moniz Bandeira (1998) comenta que, no início de 1959, a opinião de vários líderes comunistas era a de que Fidel Castro era um "aventureiro pequeno burguês", como o afirmou o Secretário Geral do Partido Comunista do Brasil, Luiz Carlos Prestes. Segue Bandeira (1998:172-173):

Esta ['um aventureiro pequeno burguês'] era a opinião generalizada entre os dirigentes comunistas atrelados às diretrizes do stalinismo, que só reconheciam como comunistas os que se filiavam ao partido, faziam trabalho organizado e submetiam-se rigorosamente à sua disciplina. Outros, ainda que declarassem marxistas-leninistas, mas não militassem em uma das células do partido, eram vistos com suspeição, como provocadores ou espióes, acusados de divisionistas, trotskistas etc. Castro, embora fosse um homem de esquerda, não merecia a confiança dos comunistas, e tinha todas as credencias para enquadrar-se em uma daquelas categorias.

O movimento revolucionário M-26-7 não possuía vínculos com o comunismo, tampouco Che Guevara, um dos grandes articuladores da Revolução, tanto que um documento da CIA, de1964, afirmava:

(...) No evidence is available to the effect that he was ever affliated with any Communist Party, although he seems to have had many contacts with party members and associates in Argentina, Guatemala and Mexico. On any count, Guevara plainly has a strong, emotional anti-US bias and a sympathetic outlook toward Communism. He especially condemns the US role in replacing the pro-Communist Arbenz government in Guatemala with a military junta in 1954. (... $)^{8}$

Um outro elemento interessante dessa desvinculação dos acontecimentos em Cuba, em relação à URSS, foi o fato de os dois países só haverem estabelecido relaçôes diplomáticas em maio de 1960, passados mais de 17 meses da Revolução.

\section{Conseqüências imediatas da Revolução Cubana}

Em pronunciamento feito em maio de 1959, Fidel Castro rejeitou explicitamente a acusação de que a Revolução era comunista ou que ele estivesse comprometido com qualquer ideologia, afirmando que:

Nuestra Revolución no es comunista, (...) nuestros ideales se apartan de la doctrina comunista, la Revolución cubana no es capitalista ni comunista, es una revolución propia, tiene una ideologia propia, tiene razones cubanas, es enteramente cubana y enteramente americana. (BANDEIRA, 1998:197).

De acordo com Moniz Bandeira (1998:197), inicialmente Fidel Castro buscava uma terceira via, evitando a bipolaridade ideológica da Guerra Fria, e optando um caminho que fosse, acima de tudo, cubano.

8 Documento disponível em http://www.parascope.com/articles/1197/chedoc2.htm; acesso em 12.07.2007. 
Uma das primeiras medidas (de cunho econômico) tomadas pelo novo governo foram a nacionalização da companhia telefônica do país, de investimento norte-americano (em 3.3.59) e a publicação do Ato de Reforma Agrária, em meados de maio do mesmo ano. Essa última era considerada fundamental, já que:

Cerca de 1,5\% dos proprietários de terra, cubanos ou não-cubanos, possuíam 46\% da área nacional, e $70 \%$ possuíam apenas $12 \%$ da área nacional. (...) Segundo informaçôes oficiais do governo cubano, somente 1.114 latifúndios ocupavam $20 \%$ de todas as áreas cultiváveis de Cuba, e de todas as pessoas dedicadas à agricultura apenas 30\% eram proprietárias do solo (...). (BANDEIRA, 1998:198).

Os contatos oficiais com a URSS iniciaram-se seis meses após a tomada de Havana, em junho de 1959, e o resultado concreto foi um acordo comercial entre os dois paises, através da exportação de açúcar cubano e a importação de matérias primas como petróleo, ferro e máquinas, firmado no início de janeiro de 1960. Cinco meses depois, em 8.5.1960, Cuba e URSS estabeleceram relações diplomáticas.

Os problemas com os EUA, cujo relacionamento com Cuba tornava-se cada vez mais complicado, agravaram-se ainda mais em julho do mesmo ano. No primeiro dia do mês, o governo cubano resolveu nacionalizar as refinarias de petróleo, por se recusarem a refinar o produto soviético. Dois dias depois, os EUA retaliaram, suspendendo a compra do açúcar cubano, o que representou grande impacto econômico por ser esse país o maior mercado de destino do principal produto de exportação da ilha.

Dois dias mais tarde, as empresas e propriedades norte-americanas foram nacionalizadas. No dia 8.6.61 a URSS "resolve" o problema da exportação do açúcar, comprometendo-se a comprar o produto cubano. Azedando ainda mais o relacionamento EUA-Cuba, a ilha nacionaliza todos os bancos norte-americanos em 17.9.1960. A nacionalização de indústrias, bancos e usinas de cana viria em outubro, e a contrapartida do embargo econômico dos EUA ao país ocorreria ainda no mesmo mês.

Para vários autores, a dinâmica do cada vez mais problemático relacionamento político e econômico entre Cuba-EUA foi a causa, e não a conseqüência da aproximação cubana com a URSS, como bem demonstra Paterson (1995:159):

In mid-1960, as the revolucionary government nationalized foreign properties, the United State suspended imports of Cuban sugar and forbade U.S. exports to the island in an effort to bring down the Castro government. These strong measures only pushed Cuba toward a new economic lifeline - the Soviet Union. As Embassador Philip Bonsal explained, 'Russia came to Castro's rescue only after the United States had taken steps to overthrow him'.

No terceiro dia de 1961, EUA e Cuba rompem relaçōes diplomáticas. Pouco mais de cem dias depois ocorreria o episódio na Baía dos Porcos. 


\section{Fatores influentes na decisão da intervenção}

Questôes ideológicas, política doméstica norte-americana, sucessos passados e um histórico de interferência na região foram alguns dos fatores que pesaram na decisão do governo dos EUA de invadir Cuba aportando na Baía dos Porcos. O objetivo deste tópico não é exaurir todos os vetores importantes em se tratando de tal tema, mas sim de efetuar uma análise dos aqui considerados como sendo os mais decisivos.

Apesar do marco da intervenção direta dos EUA na região da Bacia Caribenha ter sido a guerra entre espanhóis e norte-americanos (1898) pelo controle de Cuba, alguns fatos e circunstâncias anteriores merecem destaque.

À exceção das três Guianas, Belize e das pequenas ilhas caribenhas, toda a área do continente americano situada abaixo dos EUA obteve sua independência no controle europeu, notadamente ibérico, nas três primeiras décadas do século XIX.

A visão do governo do EUA sobre esses processos de recente independência foi bem sintetizada por John Quincy Adams ${ }^{9}$, que teria dito, entre outros pensamentos semelhantes, que "o povo da América Latina é o mais ignorante, o mais fanático e o mais supersticioso de todos católicos romanos da Cristandade", e que tentativas de estabelecer governos democráticos na região eram "tão absurdas como seriam planos semelhantes para estabelecer democracias entre os pássaros, animais e peixes". (SCHOULTZ, 2000:21).

A partir do conhecimento da articulação entre potências européias na estrutura de poder da Santa Aliança, o presidente dos Estados Unidos, James Monroe $^{10}$, ao pronunciar-se perante o Congresso de seu país, em 1823, declarou sua visão a respeito da presença européia no contexto americano e do papel dos EUA perante os outros países do continente:

(...) the American continents, by the free and independent condition which they have assumed and maintain, are henceforth not to be considered as subjects for future colonization by any European powers.

(...)

We owe it, therefore, to candor and to the amicable relations existing between the United States and those powers to declare that we should consider any attempt on their part to extend their system to any portion of this hemisphere as dangerous to our peace and safety.(...) with the Governments who have declared their independence and maintain it, and whose independence we have, on great consideration and on just principles, acknowledged, we could not view any interposition for the purpose of oppressing them, or controlling in any other manner their destiny, by any European power in any other light than as the manifestation of an unfriendly disposition toward the United States. (...)" 11

9 John Quincy Adams foi secretário de Estado dos Estados Unidos (1817-1825) e presidente do país (1825-1829). 10 Presidente de 1817 a 1825.

11 A chamada "Doutrina Monroe" foi apresentada ao Congresso, pelo Presidente, em 02/12/1823. 
Os feitos, em termos de orientação e justificação da política externa dos EUA para o continente, são colocados de forma precisa por Kissinger (2001:34-35):

Sob o guarda-chuva da Doutrina Monroe, os EUA poderiam seguir políticas nada diferentes dos sonhos de qualquer rei europeu - expandir comércio e influência, anexar territórios - em suma, transformar-se em Grande Potência sem ser necessária uma política de poder. (...) Não considerando expansão como política externa, os Estados Unidos podiam utilizar seu poder para o domínio - sobre os índios, sobre o México, no Texas - e fazê-lo de consciência tranqüila.

(...)

Em outras palavras, a Doutrina Monroe justificava a intervenção americana não só contra uma ameaça existente, mas contra qualquer possibilidade de ameaça - tal qual o equilíbrio de poder europeu.

A expansão do território dos EUA rumo ao Oeste também teve sua influência sobre a visão dos governos e de certos setores da sociedade a respeito do limite físico cabível ao país. ${ }^{12}$ Esse alargamento foi baseado numa "rude teoria de determinismo histórico"13, já que se pregava que a pressão e direção ao Pacífico eram nada mais que o cumprimento do destino da raça anglo-saxônica, ciente de que essa posição era desejo da Providência Divina. Dessa forma, a natureza, o destino e Deus moviam e justificavam a presença dos EUA pela América - física, moral e economicamente.

Assim, a interferência direta e indireta do país no seu entorno geográfico inicia-se no século XIX. No entanto, o processo intervencionista dos EUA nos países da América Central e do Caribe passou a ocorrer, de forma sistemática, somente após a guerra entre os EUA e a Espanha, no final do século XIX, tendo como foco o controle de Cuba.

\section{Do Big Stick à Política da Boa Vizinhança}

O governo do presidente Theodore "Teddy" Roosevelt (1901-1909), que inicia a política externa dos EUA do século XX, foi marcado por sua reinterpretação da Doutrina Monroe, que acabou por se chamar "Corolário Roosevelt". Este afirmava que deveria haver uma prevenção do estabelecimento de bases de países estrangeiros (i.e., europeus) no Caribe, assim como afirmava que somente seu país detinha o direito de intervir no continente. Sua política foi direcionada especialmente para as crises financeiras da Venezuela (1902) e da República Dominicana (1904).

Além disso, Teddy Roosevelt patrocinou a independência do Panamá da Colômbia (em 1901), já visando a criação do Canal do Panamá. O tratado Hay-

12 Quem mais sofreu com esse processo foi o México, que perdeu aproximadamente 1/3 de seu território para seu vizinho ao norte.

13 Expressão utilizada por Kiernan (2005:12). 
Bunau-Varilla estabeleceu o direito dos EUA de construir o Canal, assim como de manter o controle sobre ele e seu entorno (Zona do Canal) de forma soberana, situação que se manteria até o final dos anos 70. Uma de suas frases preferidas veio a marcar seu estilo de relacionamento com a América Latina: "Speak softly and carry a big stick" - ou seja, "fale suavemente e carregue um grande porrete", cujo espírito levou para seu relacionamento com a região do Mar do Caribe, já que, durante seu governo, ainda foram promovidas intervenções na República Dominicana (1904), México (1905), Honduras (1905 e 1907), Cuba (1906) e Panamá (1908).

O presidente seguinte, Howad Taft (1909-1913), continuou a política de Teddy Roosevelt de expandir a presença dos EUA no exterior (notadamente nas Américas Central e do Sul e Ásia) pelo comércio internacional, através de empresas e empresários, cunhando assim sua política externa como "dollar diplomacy". Interveio ativamente na América Central, com o envio de tropas militares para a Nicarágua (1909, 1910 e 1912), Honduras (1911) e Cuba (1912), como forma de garantir os interesses americanos na região.

Woodrow Wilson (1913-1921), por sua vez, apesar de apresentar um discurso voltado para a defesa da autodeterminação dos povos no seu famoso pronunciamento dos "14 Pontos", imaginou esse princípio sendo válido para povos "civilizados", o que não abrangeria o caso da América Central e do Caribe. Essa visão ficou patente no fato de que, durante sua gestão, ocorreram intervenções no México (1914, 1916 e 1917), Haiti (de 1915 a 1934), República Dominicana (de 1916 a 1924), Cuba (1917) e Panamá (1918). Moniz Bandeira (1998) argumenta que a promessa de Wilson de repudiar o big stick e a dollar diplomacy republicanas existiram apenas no campo retórico.

Warren Harding (1921-1925) e Calvin Coolidge (1925-1929) mantiveram o mesmo estilo de padrão de relacionamento dos EUA com a região. O primeiro pressionou para que a Guatemala mudasse o presidente para um mais favorável aos investimentos da United Fruit Company; o segundo interveio na Nicarágua, em 1926.

Em 1927, o vice ministro de Relações Exteriores dos EUA, Robert Olds, escreveu uma síntese da política externa de seu país para a região à época:

... we do control the destinies of Central America and we do so for the reason that the national interest absolutely dictates such a course. There is no room for any outside influence other than ours in this region. We could not tolerate such a thing without incurring grave risks... Central America has always understood that governments which we recognize and support stay in power while those we do not recognize and support fall. ${ }^{14}$

14 In: Memorando Confidential do vice ministro de Relações Exteriores dos EUA, Robert Olds, datado de 02 de Janeiro de 1927. Fonte: National Archives, Record Group 59, Document 817.00/4456. 
As duas administrações seguintes mudaram o padrão intervencionista das últimas décadas. Herbert Hoover (1929-1933) repudiou o "Corolário Roosevelt"15; retirou as tropas norte-americanas da Nicarágua e iniciou o processo para que o mesmo ocorresse no Haiti; foi o árbitro da Guerra do Pacífico, envolvendo Chile, Peru e Bolívia, além de ter realizado viagem de dez semanas por dez países da América Latina. Em seu discurso ao Congresso americano, em 1929, afirmou: "Nós ainda temos marines em território estrangeiro - na Nicarágua, Haiti e China. De uma forma geral, nós não desejamos ser representados no exterior dessa forma". ${ }^{16}$ Por essas palavras e ações, é justo afirma que a "Política da Boa Vizinhança", adotada e reconhecida como sendo de seu sucessor, teve, na verdade, suas bases traçadas e calcadas ainda na administração de H. Hoover. O seu sucessor, Franklin D. Roosevelt (1933-1945), consolidou esse movimento de aproximação com os outros países do continente, apesar de não ser correto imaginar que suas ações foram cheias de ética e moralidade em todos os aspectos. Foi deixada de lado a posição direcionada para intervençôes militares, é verdade, mas o direito de aplicar pressōes políticas ou econômicas pelo continente não foi abandonado. (SCHULZINGER, 1998:155)

A seu favor, Franklin Delano Roosevelt contava com o fato de haver denunciado a Emenda Platt (1934) e o controle direto que esse texto impunha sobre Cuba, e de abrir mão do direito de intervenção unilateral nos países americanos. Por outro lado, seu pior legado foi ter apoiado pelo menos dois notórios ditadores: Anastacio Somoza ${ }^{17}$, da Nicarágua, e Fulgêncio Batista, de Cuba. A política de Roosevelt para a América Latina como um todo, que durou até o final da Segunda Guerra Mundial, em 1945, pode ser sintetizada da seguinte forma:

Nenhuma mudança significativa ocorreu abaixo da superfície, nem houve uma mudança nos interesses dos EUA (...). A afirmação de Tucídides - 'grandes naçôes fazem o que querem, enquanto pequenas naçōes aceitam o que devem' - permanecia o princípio orientador das relaçôes internacionais. Talvez por que suavizava esta realidade, a nova atitude de respeito superficial foi bem recebida por muitos latinoamericanos. (SCHOULTZ, 2000:347)

É importante ressaltar que as ações dos EUA para a América Latina foram ficando cada vez mais amigáveis à medida que a Segunda Guerra Mundial se aproximava, já que a presença alemã e a ideologia fascista ítalo-germânica aumentavam cada vez mais na região. No entanto, ao passo que o conflito foi se aproximando de seu final

15 No seu lugar, adotou o chamado "Memorando Clark", que questionava a legalidade da intervenção dos EUA na América Latina.

16 "State of the Union", de 03/12/1929.

17 É famosa a frase que F.D.R. teria dito quando questionado sobre a (falta de) lógica dos EUA adotarem a Política de Boa Vizinhança na região, enquanto apoiavam o ditador da Nicarágua: "Hés a son of a bitch, but he's our son of a bitch". 
vitorioso para as forças Aliadas, a importância das concessões à América Latina foram ficando cada vez menos necessárias.

\section{Truman, Eisenhower e a América Latina}

Com o fim da Segunda Guerra Mundial, as Relações Internacionais mundiais passaram a ser guiadas pela nova realidade de um mundo dividido por duas grandes esferas de influência: uma encabeçada pelos EUA, capitalista, ao "oeste"; e outra, comunista e ao "leste", com a URSS como líder. O continente americano, nesse contexto, foi visto como uma esfera "naturalmente" norte-americana. Como afirma Saraiva (2001:34), “(...) os países latino-americanos participaram do ocidentalismo da Guerra Fria. A região ficaria aceita como área de natural influência dos Estados Unidos. A União Soviética, portanto, não poderia reivindicar espaços." Bandeira (1998) completa a explicação desse contexto da seguinte forma:

(...) se bem que verbalmente condenassem as políticas de esfera de influência e equilíbrio de poder, apelando para uma era de paz apoiada na segurança coletiva da ONU, os EUA não estavam dispostos a renunciar à hegemonia na América Latina. (1998:91)

(...) assim como a URSS não tolerava eleições livres nos países do Leste Europeu sob seu domínio, por que os anticomunistas poderiam vencê-las, os EUA (...) passaram a fomentar golpes de Estado e sustentar igualmente ditaduras, de forma a conservar sua hegemonia na região, impedindo que eleiçôes livres levassem ali forças nacionalistas e anti-norte-americanas, percebidas como comunistas, ao poder. (1998:92)

A preocupação do presidente norte-americano Henry Truman (19451953), no tocante à sua política externa, foi "conter" a expansão do comunismo pelo mundo. No entanto, a compreensão do que seria efetivamente um governo comunista era bastante abrangente, e, na prática, acabou como sendo empregada para designar qualquer governo que não quisesse se submeter, de forma automática, às pretensões e interesses de seu país. Até mesmo um país que se auto-intitulasse "neutro" no conflito EUA x URSS era considerado como sendo "inimigo". Isso por que, pela ótica da política externa norte-americana da época, a verdadeira luta travada era entre o Bem e o Mal, ou Deus e o Diabo (ou analogia semelhante), e ser neutro entre esses dois já era estar aceitando as "forças malignas". Isso implicou, também para o governo de Dwight Eisenhower (1953-1961), que propostas tendentes à esquerda, como reforma agrária, controle de emissão de lucros ao exterior, ou projetos de visão nacionalistas fossem imediatamente taxados de comunistas, mesmo que essa ideologia ou o Partido Comunista local não estivessem envolvidos a nível significativo.

Assim, ao mesmo tempo em que exerceu profundo impacto na influência dos EUA na América Latina, e, mais ainda, no contexto dos países do entorno 
caribenho, a Guerra Fria não alterou em nada a forma do relacionamento. Essa ambigüidade se explica no fato de haver a mudança no "porquê" da ação norteamericana (evitar a "contaminação" comunista"), mas não no "como" através de intervençôes políticas, econômicas e militares.

\section{Intervenção na Guatemala - Operação PB Success}

Em 1951, subiu ao poder, como Primeiro Ministro do Irã, Mohamed Mossadeq; no mesmo ano, decidiu nacionalizar o petróleo da Companhia Anglo-Iraniana de Petróleo. Durante os dois anos seguintes as maiores empresas de refino e distribuição de petróleo boicotaram o petróleo iraniano, gerando graves consequiências na economia do país. Em 1953, Mossadeq acenou para a possibilidade de solicitar ajuda à União Soviética, já que os EUA haviam recusado seu pedido, fato que levou o governo americano a utilizar uma nova forma de "controle" em outros países: a derrubada de governos através de ações secretas da Agência Central de Inteligência (CIA). A ação, denominada Operation Ajax, conduzida pela CIA em parceria com o setor iraniano descontente com a decisão de Mossadeq, foi bem-sucedida. A seu final, o primeiro ministro foi destituído do poder, voltando a governar o Xá Reza Pahlevi, que colocou de lado qualquer aliança com a URSS e garantiu o retorno dos interesses ocidentais sobre o petróleo do país.

As vantagens dessa nova "abordagem", chamadas de "covert actions" eram várias: poderia ser mais facilmente negada, pois não contava com uma invasão militar "tradicional”; não era conhecida pelo público doméstico norte-americano, já que eram, por natureza, secretas; baixo custo, envolvendo líderes e estruturas locais na mudança de poder, tendo a CIA para "guiá-los" e financiá-los, entre várias outras vantagens. Aa ações promovida pela Agência também envolviam elementos mais sutis de persuasão, como, por exemplo, pagamentos a jornais e jornalistas para noticiarem determinadas informaçôes, e "criação" de uma situação caótica ou, no mínimo, de (aparente) descontrole do atual governo.

Por esses e outro motivos, o governo dos EUA decidiu usar o mesmo tipo de abordagem no ano seguinte, em 1954, para destituir outro governo, dessa vez o do guatemalteco Jacobo Arbenz. O governo de Arbenz, que havia subido ao poder em 1950, tinha um cunho nacionalista. Uma das principais medidas, defendida como fundamental para melhorar a qualidade de vida da população, era a promoção de uma ampla reforma agrária no país, onde apenas $2 \%$ da população controlava $70 \%$ da terra (PATTERSON, 1955:132). No entanto, as principais áreas que seriam destinadas a essa reforma pertenciam à United Fruit Company, empresa cujos interesses envolviam as mais altas autoridades norte-americanas. ${ }^{18}$

18 Como exemplos: o Secretário de Estado, John Foster Dulles, fazia parte do escritório jurídico encarregado da empresa (seu irmão, Allen Dulles, era o diretor da CIA à época). 
A combinação de reforma agrária, movimentos sociais, desconsideração dos interesses políticos e econômicos dos EUA, e perdas econômicas para a United Fruit Company levaram, sem grandes dificuldades, as referidas autoridades do governo dos EUA a afirmar que tudo era obra de uma "infiltração comunista" na Guatemala.

O embaixador dos EUA no país, John Peurifoy, assegurou a um comitê de congressistas que havia passado seis horas conversando com Arbenz, e que ele falava como um comunista, pensava como um comunista, agia como um comunista, e que, se ainda não fosse um, estava no caminho de sê-lo. No entanto, como ressalta Moniz Bandeira (1998:122), "o comunismo tinha raízes fracas na Guatemala e nunca houve evidência convincente de que os comunistas dominassem o governo de Arbenz". Patterson (1995) afirma que, na verdade, a União Soviética tinha pouco interesse na América Latina nos anos 50, e que olhava com ceticismo para Arbenz e outros esquerdistas anti-americanos, que pareciam ser mais reformistas do que comunistas.

Ainda assim, o presidente dos Estados Unidos, Dwight Eisenhower, satisfeito com o resultado da operação secreta no Irã, entendeu a questão da Guatemala como uma presença comunista na América Central, e autorizou a Operação PBSUCCESS, que deveria derrubar Jacobo Arbenz do poder da Guatemala. Afinal, como bem colocou o memorando (secreto) norte-americano "Nossa Política Guatemalteca" (IN: SCHOULTZ, 2000:378):

A ameaça real e direta que a Guatemala representa apresenta para seus vizinhos é a da subversão política através de intriga através-da-fronteira que é uma característica normal do cenário centro-americano. O perigo é de contágio comunista e é mais imediato em relação aos vizinhos mais próximos da Guatemala. A infecção comunista não vai se espalhar para os EUA, mas se com tempo espalhar-se sobre boa parte da América Latina, isto afetaria a segurança do Hemisfério, e, portanto, dos EUA.

Na metade de 1954, ao custo de algo entre US\$ 5 a 7 milhões, destinados em boa parte ao pagamento de mercenários treinados pela CIA, a operação foi iniciada, sendo a ponte guatemalteca na derrubada de Arbenz liderada pelo General Castillo Armas. A capitulação do presidente foi proclamada como uma "vitória do Mundo Livre" pelo secretário de Estado dos EUA e pelo diretor da CIA, mesmo que a Guatemala vivesse, desde 1944, uma democracia constitucionalista, representativa e pluralista (BANDEIRA, 1998:135-6).

Como argumenta Schoultz (2000:380), um dos impactos da questão guatemalteca quanto à futura questão cubana pode ser entendido da seguinte forma: "no restante da década de 50, a meta primeira da política dos Estados Unidos em relação à América Latina foi evitar 'uma outra Guatemala.." 


\section{Política Externa e Interna dos EUA frente ao governo de Fidel Castro}

Em $1^{\circ}$ de janeiro de 1959, o período de Dwight Eisenhower como presidente dos EUA já estava caminhando para seu final. Tendo assumido em 1953, fora reeleito para cumprir novo mandato até janeiro de 1961. Levandose em conta que a campanha para a próxima presidência havia sido iniciada na segunda metade de 1960, sua força política "real” em relação à questão cubana durou aproximadamente 18 meses.

De acordo com Lars Schoultz (2000), no início, a administração Eisenhower não sabia como entender o novo líder cubano. No entanto, com o passar dos meses, o descontentamento do governo norte-americano com Fidel foi crescendo. Além do mais, denúncias quanto ao desrespeito ao direito à propriedade privada em Cuba (que passou a ser "violado"), o fortalecimento cubano cada vez maior de seu não-alinhamento com os EUA em questôes internacionais, e a eliminação (prisão e assassinato) dos aliados do antigo governo de Batista, não deixaram muito espaço para um contra-golpe de um governo "moderado", aliado aos interesses norte-americanos.

A preocupação de um alastramento de revoluções pela América Latina e Caribe também preocupava enormemente a administração:

(...) [tendo em vista] a grave ameaça à estabilidade da região, onde os EUA, além de enormes interesses econômicos, possuíam concessōes militares, tais como quartéis, base áreas de treinamento, centros de pesquisa e estaçôes de acompanhamento de foguetes consideradas necessárias à defesa e à segurança do Hemisfério. $\mathrm{O}$ acesso a essas concessóes, nos diversos países, variava da virtual soberania 'in perpetuity' na Zona do Canal do Panamá ao acordo com a República Dominicana para a manutenção por 10 anos de uma base de acompanhamento de foguetes. (BANDEIRA, 1998:190-191).

O problema maior não era necessariamente o comunismo per se, mas (talvez muito mais) os efeitos de movimentos nacionalistas e anti-norte-americanos na região, cujos prejuízos reais seriam bem mais desastrosos do que apenas o aspecto ideológico. De acordo com Michael Warner, a administração Eisenhower e a CIA decidiram, ao final de 1959, que Fidel Castro era um instrumento do Comunismo e aliado da URSS. A avaliação era que o descontentamento popular contra o governo de Fidel só teria alguma força por meio de um "choque externo", e a primavera de 1961 foi avaliada como a última oportunidade para administrar tal "choque" sem a participação efetiva de tropas militares norte-americanas. No entanto, o governo Eisenhower só ficaria no poder até o início de janeiro de 1961, o que complicava o comando da intervenção. Ainda assim, o planejamento para a operação iniciou-se em março de 1960, com o presidente Eisenhower ordenando a CIA que treinasse exilados cubanos para invadirem a ilha. No entanto, razōes políticas e eleitorais impediram que o plano fosse colocado em prática. 
O presidente que iria efetivar a decisão de invadir Cuba, o democrata John F. Kennedy, venceu a eleição em novembro de 1960 com apenas uma pequena margem sobre seu adversário, Richard Nixon, vice-presidente do republicano Eisenhower. Além de herdar uma economia lenta, uma possível inferioridade frente aos mísseis soviéticos, a instabilidade quanto à situação de Berlim e o perigo do avanço comunista no sudeste asiático, a "questão cubana" se apresentava, talvez, como o primeiro desafio de política externa a ser solucionado.

De acordo com o secretário de Defesa da administração Kennedy, Robert McNamara $^{19}$, o ex-presidente Eisenhower pessoalmente não era antagônico ao que se passava em Cuba, mas essa visão não era compartilhada pela população americana, que continuou com suas crenças independente da mudança presidencial. Segundo ele, a percepção geral era a de que Cuba estava sob o controle dos soviéticos, que Fidel havia se colocado do "lado" soviético, e que era provável que os soviéticos usassem Cuba como base, figurada ou literalmente, para subverter governos e possivelmente aumentar o poder militar no hemisfério. Esse posicionamento da população dos EUA quanto a Cuba foi herdada pela nova administração, que não poderia deixar de lado o caráter "doméstico" da questão cubana e de como ela deveria ser trabalhada.

No discurso inaugural, Kennedy deixou claro à população de seu país qual sua visão sobre como enfrentaria a Guerra Fria: "Let every nation know, whether it wishes us well or ill, that we shall pay any price, bear any burden, meet any hardship, support any friend, oppose any foe, in order to assure the survival and the success of liberty." Ou seja, uma interpretação desse trecho permite argumentar que, para a nova administração, a liberdade - no caso, a liberdade de Cuba e da América Latina do Comunismo e da influência soviética - era um fim pelo qual todos os meios seriam válidos.

Mesmo que Cuba não fosse uma marionete soviética ou um perigo imediato ao governo norte-americano, o presidente Kennedy parece ter ignorado as "contribuiçōes" históricas dos EUA para a formação do discurso anti-norteamericano de Fidel Castro. Seu governo definiu a ilha, de certa forma, como novo campo de batalha da Guerra Fria, decidindo remover a "irritação" cubana.

A experiência bem sucedida da invasão à Guatemala, dessa vez mirada em Cuba, teve a garantia da CIA de que seria repetida. A agência previu o levante do povo cubano contra Fidel Castro, e assegurou ao presidente dos EUA que não seria necessário o envolvimento direto (visível) do governo norte-americano. Kennedy havia discutido a questão cubana e a saída/retirada de Fidel durante sua campanha presidencial, e as garantias da CIA pareciam incontestáveis ${ }^{20}$ (PATERSON, 1995:159). Cabe ressaltar que uma das recomendações dadas pela

19 Entrevista disponível em http://www.gwu.edu/ -nsarchiv/coldwar/interviews/episode-10/mcnamara1.html; acesso em 21.7.2007.

20 Sobre a participação da CIA no evento de forma mais detalhada, sugere-se: http://www.foia.cia.gov/bay_of_ pigs.asp 
agência para que a empreitada fosse bem-sucedida foi a de que o líder cubano fosse "neutralizado" - um eufemismo para um plano de assassinato - durante ou pouco antes da invasão. ${ }^{21}$

Para um presidente que havia vencido a eleição com uma tão pequena margem e com um discurso anti-comunista tão ferrenho, parecia proveitosa a idéia de iniciar o mandato consolidando seu poder de liderança pela derrubada do governo cubano. O presidente Kennedy aprovou a invasão em abril de 1961, mas proibiu expressamente a participação direta dos militares dos EUA na ação ${ }^{22}$. Sua intenção era poder negar o envolvimento do país com os acontecimentos, de forma a preservar sua reputação de progressista na América Latina ${ }^{23}$ e evitar provocar os aliados soviéticos de Fidel Castro.

\section{As conseqüências}

O fracasso da iniciativa foi um duro golpe para o novo governo dos EUA, no poder a apenas três meses. Os impactos no contexto doméstico e internacional foram vários, todos negativos. Internamente, o incidente fez com que Kennedy parecesse inapto, inexperiente e inseguro. $\mathrm{O}$ presidente colocou a maior parte da culpa na CIA, e o diretor-geral da Agência, Allen Dulles, entre outras altas autoridades, foram responsabilizadas e postas para fora da instituição. No entanto, Kennedy foi forçado a admitir publicamente a responsabilidade pela invasão.

É possível argumentar que o fiasco da invasão a Cuba fez com que Kennedy, para não parecer ainda mais fragilizado perante a população, resolvesse, a partir de então, endurecer ainda mais o discurso anti-comunista, e continuar a perseguir a queda de Castro. Durante o ano seguinte, os EUA impuseram um bloqueio econômico ainda mais rígido, conseguiram expulsar a ilha da Organização dos Estados Americanos (OEA), recusaram-se a reconhecer o governo de Fidel Castro, utilizaram propaganda subversiva contra o líder cubano, além de continuarem com os planos para assassiná-lo. Afinal, os EUA já haviam "perdido" a China para os comunistas (em 1949), e tudo era válido para reverter a "perda" de Cuba.

Externamente, o presidente da URSS aproveitou a oportunidade para atacar seu grande nêmesis, discursando que os EUA defendiam o colonialismo e ditadores, e que havia atacado um governo apoiado pela população local apenas por não se submeter a ele. No entanto, ficou claro que os soviéticos estavam em uma situação delicada para julgar Kennedy, posto que, de certa forma, a invasão a Cuba foi o equivalente norte-americano do que havia sido feito pela União

21 Ver a entrevista com Howard Hunt, ex-agente da CIA: http://edition.cnn.com/SPECIALS/cold.war/ episodes/18/interviews/hunt/

22 Nem todos os membros do gabinete de Kennedy ou altas autoridades aprovavam a iniciativa, como o secretário de Relaçōes Exteriores, Dean Rusk, seu Vice, Chester A. Bowles, e o Sen. William Fulbright, presidente da Comissão de Relações Exteriores do Senado, entre outros.

23 Uma dessas iniciativas seria dada em março de 1961, com o lançamento do projeto "Aliança para o Progresso". 
Soviética na Hungria, em 1956, ao destituir o governo popular de Imre Nagy. Ainda assim, a ação comprometeu a imagem que Kennedy buscava passar para a opinião pública mundial, de um defensor e guardião de elevados princípios morais e políticos, além de manchar, ainda mais, a imagem dos EUA perante a América Latina. Em Cuba, a intervenção fez de Fidel Castro uma figura de crescente popularidade, e funcionou por projetá-lo de vez para a órbita da União Soviética, demonstrada com sua declaração, em dezembro de 1961, da adoção da doutrina marxista-leninista.

\section{Conclusão}

A política de intervenção dos EUA em Cuba antecedeu em várias décadas o episódio da Baía dos Porcos. No entanto, um dos importantes diferenciais desta ação em relação a outras passadas é que, desta vez, o governo cubano, por razões ideológicas, não aceitaria de forma alguma a participação norte-americana em suas decisóes, colocando-se disposto a lutar (até a morte, se necessário) por esse princípio, contando com o apoio da grande maioria população local.

O que se tira de uma análise da motivação por trás da iniciativa é que não se tratou de decisão tomada somente com base em questôes imediatas, mas sim sob o direcionamento de vários fatores: estruturas históricas de relacionamento dos EUA com os países do entorno caribenho; o sucesso recente de operações secretas ("covert actions") de retiradas de governos "inconvenientes" aos EUA (Irã e, especialmente, Guatemala), assim como pela política externa norte-americana e pressão da opinião pública doméstica em relação à Guerra Fria e ao governo de Fidel Castro.

Por vezes ofuscado na história pela Crise dos Mísseis (que ocorreria no ano seguinte), e que levaria o mundo ao limiar da terceira Guerra Mundial, a frustrada invasão norte-americana ao território cubano, apesar de não ter sido tão dramática, não deixa de ser marcante como um elemento importante de história de Cuba, da América Latina e dos EUA no contexto da Guerra Fria.

Recebido em 14 de agosto de 2007 Aprovado em 30 de abril de 2008

\section{Referências bibliográficas}

AYERBE, Luis Fernando. Estados Unidos e América Latina - a construção da hegemonia. São Paulo: UNESP, 2002.

BANDEIRA, Luiz Aberto Moniz. De Martí a Fidel - a Revolução Cubana e a América Latina. Rio de Janeiro: Civilização Brasileira, 1998.

DIVINE, Robert. Eisenhower and the Cold War. Oxford (GB): Oxford University Press, 1981. 
FRANKEL, Max. High Noon in the Cold War-Kennedy, Khruschev and the Cuban Missile Crisis. Nova Iorque (EUA): Ballantine Books, 2004.

KIERNAN, V.G. America: the new imperialism - from white settlement to world hegemony. Nova Iorque: Verso, 2005.

KISSINGER, Henry. Diplomacia. Rio de Janeiro: Livraria Francisco Alves, 2001.

PECEQUILO, Cristina S. A Politica Externa dos Estados Unidos. Porto Alegre: UFRGS, 2003.

PETERSON, Thomas e J. G. CLIFFORD. America Ascendant-U.S. Foreign Relations since 1939. Lexington, MA (EUA): D.C. Heath and Company, 1995.

SARAIVA, José Flávio Sombra. "Dois Gigantes e um condomínio: da Guerra Fria à Coexistência Pacífica”. in: Relaçôes Internacionais: dois séculos de História: entre a ordem bipolar e o policentrismol José Flávio Sombra Saraiva (org.). Brasília: IBRI, 2001

SCHOULTZ, Lars. Estados Unidos: poder e submissão. Bauru: EDUSC, 2000.

SCHULZINGER, Robert. U.S. Diplomacy since 1900. Nova Iorque: Oxford Universty Press, 1998. 4a Edição.

WARNER, Michael. "Lessons Unlearned - The CIA's Internal Probe of the Bay of Pigs Affair". Studies in Inteligence. CIA: Winter 1998-1999. Disponível em http://www.cia.gov/csi/studies/ winter98_99/art08.html; acesso em 1.8.2007.

\section{Resumo}

A decisão do governo dos Estados Unidos de invadir Cuba, em abril de 1961, foi resultado de uma combinação de vários fatores históricos e políticos. Entre eles, a continuidade das interferências dos Estados Unidos no contexto do entorno caribenho, de forma direta (entre o início do século XX até o início dos anos 1930), e, mais tarde, de forma indireta; as bem sucedidas intervenções promovidas pela CIA no Irã (1953) e na Guatemala (1954); além da "necessidade" política, no plano doméstico, do recém-eleito presidente Kennedy de demonstrar o quão comprometido estava com a contenção do comunismo. Ou seja, nenhum fator isolado pode explicar, sozinho, a decisão de ir em frente com um plano que findou por ser um grande fracasso político para o governo dos EUA.

\section{Abstract}

The decision of the United States government to intervene in Cuba, in April 1961, was the result of a combination of historical and political factors. Among them, the history of US interference in the Caribbean context, both directly (between the beginning of the $20^{\text {th }}$ century up to the first years of the 1930's), and, later on, indirectly; the successful interventions promoted by the CIA in Iran (1953) and Guatemala (1954); as well as the political "need", domestically, of recently elected president Kennedy to demonstrate how committed he was with containing communism. Thus, no single factor can solely explain the decision to go ahead with the plan, which turned out to be a huge political failure for the US government.

Palavras-chave: História de Cuba, História da América Central, Política Externa dos Estados Unidos, Guerra Fria.

Keywords: History of Cuba, History of Central America, US Foreign Policy, Cold War. 